\title{
Globe
}

Revue internationale d'études québécoises

\section{Les Langues du roman. Du plurilinguisme comme stratégie textuelle, Sous la direction de Lise Gauvin, Les Presses de l’Université de Montréal, « Espace littéraire », 1999, 178 p.}

\section{John Kristian Sanaker}

Volume 2, numéro 2, 1999

URI : https://id.erudit.org/iderudit/1000475ar

DOI : https://doi.org/10.7202/1000475ar

Aller au sommaire du numéro

Éditeur(s)

Globe, Revue internationale d'études québécoises

ISSN

1481-5869 (imprimé)

1923-8231 (numérique)

Découvrir la revue

Citer ce compte rendu

Sanaker, J. K. (1999). Compte rendu de [Les Langues du roman. Du plurilinguisme comme stratégie textuelle, Sous la direction de Lise Gauvin, Les Presses de l’Université de Montréal, «Espace littéraire », 1999, 178 p.] Globe, 2(2), 164-165. https://doi.org/10.7202/1000475ar d'utilisation que vous pouvez consulter en ligne.

https://apropos.erudit.org/fr/usagers/politique-dutilisation/ 


\section{REVUE INTERNATIONALE D'ÉTUDES QUÉBÉCOISES}

raison Gilles Paquet, est que l'État québécois fait peu de cas dans son mode de gestion politique de la société civile québécoise qui existe et n'a pas été totalement décapitée par la Révolution tranquille. Cependant, il s'agit d'un problème de gestion des relations Étatsociété, plutôt que de croissance économique, qui est du ressort du politique et sur lequel l'auteur aurait eu intérêt à concentrer sa critique.

Luc Turgeon Université McGill

\section{Les Langues du roman. \\ Du plurilinguisme comme stratégie textuelle}

Sous la direction de Lise Gauvin,

Les Presses de l'Université de Montréal,

«Espace littéraire», 1999, 178p.

Le présent ouvrage s'inscrit dans un courant de la critique et de la théorie littéraires qui est déjà bien établi, à savoir celui qui étudie les rapports entre la littérature et une société donnée dans l'optique de la langue littéraire comme manifestation d'une certaine hétérogénéité linguistique. Quelles sont les stratégies mises en œuvre par les écrivains pour rendre compte de la mixité linguistique d'une société de référence donnée? $\mathrm{Si}$ le domaine francophone s'est avéré particulièrement riche comme domaine d'investigation dans cette optique, c'est qu'on y trouve partout une rencontre de langues et de cultures. De l'Afrique au Québec, en passant par les Antilles, le français coexistent avec d'autres langues, et le frottement linguistique et culturel qui en résulte produit des effets intéressants dans le domaine de la littérature. Pour rendre compte de l'attitude active de l'écrivain qui se trouve ainsi, dans son entre-deux-langues, dans la nécessité d'opter pour une stratégie spécifique, Lise Gauvin a proposé le terme heureux de surconscience linguistique, terme qu'elle a déjà présenté et discuté dans plusieurs articles, et qu'elle reprend ici dans son «Introduction» en se référant entre autres à Bakhtine et à Derrida. 


\section{RECENSIONS}

Ce recueil d'articles s'adresse à un public spécialisé qui possède déjà des notions de base dans le domaine du plurilinguisme littéraire. Les textes représentent des approches très diversifiées, et ils nous font parcourir la plupart des littératures francophones : Lise Gauvin discute les «effets de langue» dans Bonheur d'occasion et Le Survenant, Jean-Marie Klinkenberg montre dans quelle mesure la littérature belge contemporaine est marquée par un certain usage linguistique comme marque d'identité, Raoul Boudreau présente des exemples de la littérature acadienne qui montrent que cette littérature, écrite dans une langue "minorisée», est plus qu'aucune autre marquée par une «surconscience linguistique» («aucun [écrivain] ne peut s'installer d'emblée dans une langue qui va de soin), et Amadou Ly, Alioune Diané et Catherine Khordoc représentent l'Afrique et les Antilles, régions où une problématisation des questions linguistico-littéraires semble incontournable. Le domaine français est représenté par une étude de Rainier Grutman sur un Victor Hugo hispanisant et par celui de Georg Kremnitz sur Jorge Semprun, écrivain espagnol devenu bilingue et "schizophrène", et finalement nous sortons de la francophonie avec Ginette Michaud qui se penche sur l'importance de l'accent et de l'oralité chez Joyce.

La plupart des articles ont d'abord été présentés comme des communications à un colloque à l'Université de Montréal, mais loin d'être marqué par la qualité inégale qui est souvent liée aux actes de colloques trop généreusement ouverts à tout participant, cet ouvrage nous impressionne par sa qualité académique certaine et égale. Chaque article témoigne de la compétence de chacun des collaborateurs, qui se sont retrouvés autour de Lise Gauvin et JeanMarie Klinkenberg, fondateurs du «Groupe de recherche interuniversitaire sur les interactions langues/littératures» (GRILL). A juger d'après le présent ouvrage, c'est un groupe dont il faut suivre attentivement les activités si l'on s'intéresse à ces phénomènes mouvants et fascinants que sont les littératures francophones. 